\title{
Timefulness: an Important Conceptualization but Needing a Better Approach
}

\author{
Marcia Bjornerud (2018) Timefulness: How Thinking like a Geologist \\ Can Help Save the World. Princeton University Press. Princeton, NJ. \\ ISBN: 9870691181202, 208 Pages, Price: \$24.95 USD (Hardcover)

\section{ISBN: 9870691181202, 208 Pages, Price: \$24.95 USD (Hardcover)}

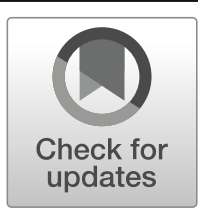

\section{Glenn Dolphin ${ }^{1}$}

Published online: 14 December 2019

(C) The Author(s) 2019

\section{Introduction}

I read Marcia Bjornerud's Timefulness: How Thinking like a Geologist Can Help Save the World on the stair machine, as I do all my books for pleasure - it is the only time I have to do such reading, thanks to my self-imposed super busy schedule. My hope was that a book focused on thinking about time might help me improve how I schedule it, or at least help me to better appreciate how I spend it. Educated as a geologist and a science educator, I am a geology instructor at a university (as well as a recovering high school Earth science teacher). With this range of teaching experience, I am very familiar with students' challenges in telling geological time, both in terms of relative dating and sequence of events, and in terms of the sheer magnitude of the age of the Earth and all that exists on it. As a concerned citizen of the Earth, I also realize that many of the problems that face humanity today are geological in nature (mineral and energy resource extraction, clean water, soil erosion, breathable air, climate change, and the various and sundry geologic hazards that threaten human life and property), and can only be solved (or at least mitigated) by understanding the phenomena involved. All this requires geological thinking.

With these concerns in mind, I had great expectations from the book: that it would lend some keen insights for my own personal benefit, but also that it would help me to help my students develop a deeper appreciation for geologic time, and the skills for thinking about and solving geological problems where time is a constituent. Indeed, Bjornerud states, "I've written this book in the belief (possibly naïve) that if more people understood our shared history and destiny as Earth-dwellers, we might treat each other, and the planet, better." (p. 19). In this vein, Timefulness does drop many pearls of wisdom about both time and systemsthinking, the latter of which is particularly emphasized. Unfortunately, while the book has

Glenn Dolphin

glenn.dolphin@ucalgary.ca 
several positive qualities, many limitations detract from these, the main one being the strong undercurrent of scientism that runs throughout the text. This stance often manifests itself in ways that can alienate those who could most benefit from this book; further, the author frequently takes a cynical tone, when a more positive message would reach an audience that is not already part of the choir. Finally, a sense of objectivism pervades the text, which undermines opportunities for readers to more closely approach thinking like a geologist.

\title{
2 The Pearls
}

Much of the literature on student difficulties in understanding geoscience phenomena reports that these troubles stem from the fact that many Earth phenomena occur on a scale of time and/or space that is well beyond the range of everyday experience. Bjornerud (pp. 21-22) recognizes this and does an effective job illustrating important points through analogies, metaphors, and other forms of comparison that bring abstract concepts into a more concrete view. She even shows how geologists approach study in their discipline:

It [geology] applied scholarly habits when associated with the study of literature and the arts - the practice of close reading, sensitivity to allusion and analogy, capacity for spatial visualization - to the examination of rocks. Its particular form of inferential logic demanded mental versatility and a vigorous but disciplined imagination. And its explanatory power was vast; it was nothing less than the etymology of the world

and

\begin{abstract}
An apt way to describe how geologists perceive rocks and landscapes is the metaphor of a palimpsest - the term used by medieval scholars to describe a parchment that was used more than once, with old ink scraped off to allow a new document to be inscribed. Invariably, the erasure was imperfect, the vestiges of the earlier work survived. These remnants can be read using x-rays and various illumination techniques, and in some cases are the only sources of very ancient documents (including several of the most important writings of Archimedes). In the same way, everywhere on Earth, traces of earlier epics persist in the contours of landforms on the rocks beneath, even as new chapters are being written. The discipline of geology is akin to an optical device for seeing the Earth text in all its dimensions. To think geologically is to hold in the mind's eye not only what is visible at the surface but also present in the subsurface, what has been and will be.
\end{abstract}

These two comparisons successfully highlight how a geologist thinks or how a geologist might approach a problem. I appreciated their development and inclusion within the text. Unfortunately, much of the way Bjornerud describes the geology in the text does not appropriately portray geology as a practice of reading the signs in the rocks and making interpretationsconstructing a story - based on those signs. I will return to this critique in section 4 .

One analogy that Bjornerud does not delve into specifically is how geologists substitute space for time. Geologists study time through how they observe the rocks. Layers, for instance, represent the passage of given amounts of time. Unconformities, areas where some of those layers are missing, then equal missing time, like missing pages (or even whole chapters) from a book. This way of making the abstract concrete represents a major way of thinking in geology but gets little mention in 
the book. Like astronomers who only have the light from stars to inform them about how the universe works, geologists have only the signs in rocks to inform them of Earth's past.

Other comparisons that Bjornerud convincingly achieves are those juxtaposing the various magnitudes of $\mathrm{CO}_{2}$ released into the atmosphere that caused tremendous warming events (and mass extinctions) with the amount of $\mathrm{CO}_{2}$ released annually by human activities. For instance, she stated that geologists estimate that 2000-6000 $\mathrm{Gt}$ of $\mathrm{CO}^{2}$ were released, which created the Paleocene-Eocene Thermal Maximum (PETM) that caused a $5^{\circ}-8^{\circ}$ increase in global temperature, approximately 55 million years ago. Estimates place our cumulative release in $\mathrm{CO}_{2}$ at approximately 500Gt, with "a quarter of that released since the year 2000" (p. 147).

Through numerous examples, Bjornerud (p.92) emphasizes that humans act on a scale of time and change that is far shorter than Earth phenomena; she describes how this difference in scale affects our understanding of our own impact:

The lingering nineteenth-century belief that Earth changes only slowly has lulled us into thinking that it is impassive and eternal, that nothing we do could alter it significantly. That notion has also caused us to view Earth's intermittent adjustments - the creation of new volcanic island, a magnitude 9 earthquake - as aberrations, when in fact these events are business as usual for the planet. We are big enough now to scratch and dent the Earth, scar, and abrade it, but we ourselves will have to live with the damage. Earth, meanwhile, will continue to make slow repairs, punctuated by sudden renovation projects that will clear away our proudest constructions.

She notes that "there is an immense asymmetry in the time it takes to consume, alter, or destroy natural phenomena compared with the time required to replace, restore, or repair them" (p. 157). This lack of temporal thinking pervades all aspects of society and can be especially harmful in places of policy. One such example she (p. 163) points to is the government in her own home state:

But the state's business-minded attorney general has ruled that the Department of Natural Resources does not have the authority to consider the compounding effects of wells in any given area, arguing it is "unfair" for the DNR to issue a well permit for one industrial dairy operation and then deny the permit to another. In doing so, the attorney general decreed both past and future irrelevant. Only the present matters.

With this passage, as with others, Bjornerud points out how the dominant socio-political context - in this case, capitalism — controls the approach to thinking timefully. In a system where the next economic quarter or next news cycle or next election cycle is the time marker that matters, it's hard to see past that into longer-term visions, possibilities, and responsibilities in the future. Despite this, however, she closes the book optimistically, looking forward to the potential the future holds: "It is something like the way parents see their growing children, poignantly remembering them at earlier stages while holding aspirational visions for who they will become" (p. 178).

Bjornerud also does a wonderful job of demonstrating another aspect of geological thinking - systems thinking. Through several instances, she never addresses the concept of Earth systems, but emphasized it even more than thinking timefully, it seemed to me. I found this fitting as I can imagine this mode of thinking as being at least as important as thinking timefully. She spoke of how chemists and physicists (primarily) had had such great success in 
the past with science, but left some tremendous environmental degradation in their wake, such as with development of plastics, nuclear energy, fertilizers and so on. However, she lets them off the hook for such environmental implications, stating that "if one is trained to think of natural systems in highly simplified ways [then one] strip[s] away the particulars so that idealized laws apply" (p.14). Similarly, she notes when "perturbations to these systems may play out over time, then the undesirable consequences of these interventions will come as a surprise" (p. 14). In contrast, she comments that "most geoscientists, acutely aware of how even small changes to the intricate natural systems can have large and unanticipated consequences, are profoundly skeptical" (p. 15) of such interventions. She (p.18) follows these observations with a rationale for why systems thinking could help us collaborate as citizens of Earth:

In fact, natural scientists already serve as a kind of impromptu international diplomatic corps who demonstrate that it is possible for people from developed and developing countries, socialist and capitalist regimes, theocracies and democracies to cooperate, debate, disagree, and move toward consensus, unified by the fact that we are all citizens of a planet whose tectonic, hydrologic, atmospheric habits ignore national boundaries.

By looking at and treating the Earth as a series of interacting systems, we are forced to give up arbitrarily drawn national boundaries because the systems themselves ignore such boundaries. Thinking this way could help to solve problems more globally and efficiently because it "can provide a politically neutral narrative from which all nations may agree to take counsel” (p. 19).

Bjornerud (p.124-125) makes systems thinking especially relevant in her treatment of the history of the atmosphere, from its evolution in the early days, through its oxygenation and its current anthropogenic changes:

\footnotetext{
The story of the atmosphere reminds us that the sky over our head is not the only, or ultimate, one to shelter the Earth. When there is change in the air, even after long periods of stability, it can blow through with breathtaking suddenness, as Svalbard's withering glaciers attest. In the aftermath of these winds of change, upheavals and biogeochemical cycles ripple through ecosystems at all levels. Organisms that have invested everything in the old world order will suffer or even be extinguished while microbes quietly clean up the mess and decree new sets of rules for the survivors. Tinkering with atmospheric chemistry is a dangerous business; ungovernable forces can come out of thin air.
}

I do not feel better enabled to think in a timefull way from Bjornerud's telling of the story of the atmospheres of Earth. Still, the implications of the connections we all have to it, and our investment in the "old world order" do give me pause. This is coupled with a stronger appreciation for being circumspect about the "quick fix" to our current climate tampering.

The world is a grand place, and that "grandeur has always included us; we have simply tormented ourselves with the idea that we are outside the garden" (p. 175). Perhaps the most powerful message of all, though Bjornerud does not explicitly state it, is this: Yes, the systems are complex and understanding them can help us influence them in meaningful ways, but we are also a part of that system, so that anything we do to the system, we do to ourselves. We will not bequeath the world to our descendants as if handing over some fortune to them, implying our separateness from that inheritance. Instead, we need to think of ourselves like bubbles on an agitated ocean-a part of the ocean with the appearance of an individual entity-that will influence the nature of future bubbles - we can affect the nature of the water, air, and dust particles since we are made of the same stuff. 


\section{Pervasive Scientism}

One strong undercurrent throughout the text is Bjornerud's implicit and explicit animosity toward religions, and especially Christian ways of knowing. At times she states that she truly empathize[s]" (p. 8) with students' distress when trying to navigate a path between science and their religious belief systems. She has "sympathy for individuals wrestling with theological questions" (p. 9). At the same time, however, she has "no tolerance" for those she claims "spread brain fogging pseudoscience" (p. 9), speaking of young Earth creationism: "The Genesis version [of Earth's story] is an offensive dumbing-down, an oversimplification so extreme as to be disrespectful to the creation" (p. 9). She also states that "you can cleave to whatever myths you like about the history of the planet, but then you should live with only the technologies that follow from that world view. And please stop dulling the minds of the next generation." (p. 11, emphasis mine).

Now, I am not going to criticize the opinions of the author. She is certainly free to have and to express whatever opinions she likes. My critique here is that if she deems religiously inclined individuals as those most in need of hearing her perspective on environmental concerns, why alienate them in the first 10 pages of the book? Why alienate them at all? Advocating a scientific world view should be one of building a solid case from solid evidence and logical reasoning. Once that is done, it is the reader's job to make up their own mind. One must remember that while science and scientific thinking have wrought remarkable developments, meaningful developments during the prescientific era (that is, prior to the Enlightenment) include language, music, art, and philosophy. In other words, the notion that nonscientific thinking is inferior in some way is dubious.

Further, it has really only been since the publishing in the early 1900s of The Fundamentals, a response by a collection of conservative Protestant writers to Darwin's On the Origin of Species which asserted a truly literal and inerrant interpretation of the Bible, that a real conflict between science and religion developed. James Ussher's 6000 year chronology for the Earth was not an attempt to constrict the age of the Earth to agree with the Bible, but was a serious scholarly endeavor to ascertain the age of the Earth, using the only known sources of evidence, texts, and where gaps existed in the Bible, Ussher used many other ancient texts to attempt to fill the gaps. Hundreds attempted this same task, including Johannes Kepler and Isaac Newton.

By using this science versus religion trope throughout the text, many of the historical anecdotes Bjornerud invokes become inaccurate. At one point, Bjornerud refers to William Thompson (Lord Kelvin) as the "high priest of thermodynamics" (p. 28). This metaphor paints a less than flattering picture of the physicist whose calculations of the age of the Earth fell far short of the time demanded by Darwin for evolution to take place, or by Lyell to account for the signs of the existence of past worlds. Thompson did believe in design in nature so Darwin's natural selection mechanism, based on randomness, did not fit his design assertion. Like Kepler and Newton, Thompson was not a pseudoscientist, nor was he dumbing down what he taught his students. He believed the science he was doing was sacred; it was not constrained to religious dogma but revealed the glory of God. His calculations were well within the realm of others, including many contemporary geologists.

Many of the early contributors to science, and geology specifically, were religious members and often high-ranking officials in the church: Steno, Comte de Buffon, Laplace, Hutton, Playfair, Buckland, and Sedgwick, to name a few. In fact, some historians have claimed that it was specifically the chronologic structure of the Bible that precipitated the revolution in thought about the Earth as having a history based on multiple contingencies of the past. 
Bjornerud also discusses the idea of catastrophism as an inherently Christian interpretation of events, when, really, it was Georges Cuvier who developed the notion of catastrophism (explicitly non-Biblical) as an explanation for mass extinctions. His goal was not to constrain the age of the Earth but to explain phenomena that were difficult to account for using uniformitarianism. Currently, our assumption about the role of past phenomena in creating the signs in the rocks - actualism-borrows portions from both uniformitarianism and catastrophism.

Going beyond the science-religion controversy, in parts of the text Bjornerud expresses scientism and the objectification of scientific knowledge that essentially disparage some historical figures. This stance also, ironically, circumvents the kind of geological thinking she so eloquently describes as necessary. As an example, I find her use of "Anthropocene," as an existing time designation, to be problematic. To my knowledge, there is only a motion to create this new epoch, but no official designation. However, she deploys it as if it is already an established designation, as in "Siberian soil bacteria that slumbered for 700,000 years...now reawakened by Anthropocene warming..." (p. 167). Such usage sends unanticipated messages to the novice reader: first, that it's warming because it is the Anthropocene period, rather than vice versa; it is the period that is constructed from the observations and not the cause of the observations. Second, she writes of the Anthropocene is an officially recognized era, which, as noted, has not yet happened. Bjornerud reveals her bias by using the term in this way. Currently, use of the term in this way certainly has political implications as well. For readers who share this bias, this will not be a problem, but it certainly excludes those who do not. At the very least, it may well become their reason to put down the book.

Bjornerud spends some time talking about the history of geology - the development of geological ideas through time. This is a good call on her part, although in some places her discussion is not valid. In other places, her historical account is incorrect. For instance, in summarizing the developments in geology over time she states, "The evolution of geology as a discipline has been similar. Simplistic Victorian ideas about the planet - the dogma of strict uniformitarianism, the belief in fixed continents, the denial of mass extinctions - have given way to a subtler, humbler understanding of an Earth that has many moods and miens, and still harbors deep secrets" (p. 177). To characterize Victorian ideas as simpler is only possible from our present vantage point. Scientists were not simpler back then. They were just as complex thinkers as geologists today, but they only had the knowledge available to them at the time. Her use of "dogma," though not incorrect here, does seem to imply a kind of closedmindedness that existed then but not now, with our "subtler and humbler understandings."

I would say that trying to differentiate past geologists from present-day ones is done at one's own peril. We are just as dogmatic about our life's work today. Just ask the paleontologists who fought hard against the impact explanation for dinosaur extinction, or those who attribute all non-plate boundary tectonics to mantle plumes: you will find plenty of dogma. The idea of mass extinction was put forth by world-renowned anatomist, Georges Cuvier, in the late eighteenth century. Certainly, by the time of Darwin's publication of The Origin it was accepted by most, as extinctions were even a part of Darwin's publication. Ironically, Cuvier did not accept the idea of evolution. It is easy to stand in the present and point out the errors of scientists of the past. What will future scientists say about us a hundred years hence? This kind of talking about the past, within the context of the present, seems to undermine the purpose of the book; in a sense, she is disregarding the past for the present.

Also, Bjornerud's objectification of geological knowledge significantly undermines other forms of "thinking like a geologist." This is not a problem unique to her, as it is a common 
approach in textbooks and reflects how much science teaching is done. That said, as the book's title underscores that her identified goal is to promote thinking like a geologist, to present knowledge in a manner inconsistent with that model of thought contradicts the goal. For instance, she states, "Mid-ocean ridges are thought to coincide with the areas of convective upwelling, where the Earth's crust is forced to stretch and thin above the rising plume of hot rock" (p. 64). As a matter of historical development, we knew about the mid-ocean ridges and then inferred that they were an expression of convection. We have observed mid-ocean ridges, not mantle convection. As another example, any introductory geology text will state that narrow zones of crustal deformation (seismic and volcanic activity) exist because the zones are at plate boundaries, yet geologists used the observations of these narrow zones of deformation to locate the boundaries in the first place. In real terms, this means that we almost always teach the inference-a construct-as something that exists and then use the signs-signs which were instrumental in building the construct-as the proof that the construct is real; the cause of the signs. This is in contrast to teaching that we observed these signs and therefore conjectured this process. As a historical and interpretive science, this is how geologists think.

Saying things like "In particular, these densest of rocks testify to changes in the air" (p. 103), and "The fossil record speaks of an ocean ecosystem in disarray" (p. 146) implies that one just walks up to an outcrop and the information is there for immediate consumption and that there is no interpretation involved, that no people participated in creating this narrative. Now, I'm pretty sure Bjornerud (or any other geologist for that matter) does not think geology happens in this simplistic way. However, novices to geology completely miss that knowledge construction crucially depends on careful observation, assumptions, inference, abductive reasoning, and creativity. If this is a book that states, "How thinking like a geologist can help save the world," then making that thinking as transparent as possible would seem to be a key goal.

\section{Some Historical and Scientific Errors}

My work as a science educator shapes how I review this book. In this vein, I find it necessary to point out some of the more important errors in the text. Because these errors are common misconceptions, I want to address them head on. Bjornerud describes a historical situation where James Hutton, while in a small boat off the coast of Scottland, sailed by a promontory called Siccar point. The rocks at Siccar Point show something that is classified as an angular unconformity. The layered shales on the bottom were oriented vertically and planed off horizontally, while the rocks above were deposited in horizontal layers. Many geologists describe the situation similarly to Bjornerud (p. 24):

He made two astoundingly interpretive leaps. First, he recognized that the underlying vertical rocks represented a former mountain range where the marine strata had been tilted by crustal upheaval. Second, he understood that the surface that truncated them represented an erosional interval long enough to wear down the mountains, and that the overlying rocks were sediments that had accumulated on top of their ruins. 
In actuality, Hutton had this idea (cycles of deformation, wasting, and deposition) pretty well fleshed out and had already presented it to the Royal Society of Edinburgh three years prior to his experience at Siccar Point. Hutton's interest in this particular location was to find evidence to support his idea of "former worlds." This was not a flash of insight, "a simple but revolutionary calculation" (p. 24); the rocks did not tell Hutton of their past. His idea was the result of decades of observations, interpretations, and conversations (with the likes of other important Scottish Enlightenment characters such as David Hume and Joseph Black) about the nature and timing of Earth's surface processes that he observed mainly while walking about his land. Bjornerud's presentation of this information overlooks that Hutton approached this site to look for evidence of an already-formed theory; that Hutton had performed all of the intellectual heavy-lifting years prior. Bjornerud (p. 24) then tries to contrast Hutton's idea to the concurrent biblically-based chronologies:

$[\mathrm{U}]$ nder the assumption that the Earth was only a few thousand years old, deeply rooted valleys and thick piles of sedimentary rock could be explained only by large magnitude catastrophic events. Hutton had replaced this worldview with the foundational idea of geology: uniformitarianism - the assumption that present-day processes are the same as those that operated in the geologic past.

The notion that "deeply rooted valleys and thick piles of sedimentary rocks" must be the result of catastrophic events, like the flood in the Bible, is yet another attempt to portray this fictional tension between the Church and science. It is noteworthy that "science" as an idea or term is not even used until the nineteenth century, when the wording shifted from "natural philosophy." Many Christians, though they did think the Earth was relatively young, also considered the surface of the Earth as unchanged since the creation. There was no need to invoke catastrophes because the observed world was static since its creation. More to the point, this inerrant fundamentalist interpretation of the Bible is a very modern phenomenon. There were catastrophists, a term coined by Georges Cuvier to explain the "violent revolutions" that caused mass extinctions. This scientific catastrophism did not predicate itself on a young Earth; rather, it was a way to explain observations where uniformitarianism did not do an adequate job (this would include deposition of glacial erratics, as water from a catastrophic flood seemed to be the only reasonable mechanism before we considered the possibility of glaciers and global ice ages).

Controversy can be a wonderful tool for teaching science. During the storytelling, however, there is a tendency, including this book, to exaggerate conflict in the history of geology. It seems like the nature of storytelling. I've already written about Bjornerud's false characterization of biblically-based young earthers versus science. Another such controversy in the history of geology revolves around William Thompson versus Charles Lyell and Charles Darwin, concerning efforts to discern the age of the Earth. Bjornerud states that Thompson's insistence on a 20-million-year-old Earth was wrong and that "frustrated geologists attempted to reclaim the question" (p. 29) of the age of the Earth by using the thickness of sedimentary rocks divided by a sedimentation rate that "yielded ages of hundreds of millions to billions of years." This is only partially accurate. There were some geologists whose calculations had the Earth at around hundreds of millions to billions of years old, but most of the calculations were an order of magnitude smaller (3 million to 100 million years old), thus more aligned with Thompson's calculations. Comte du Buffon had calculated Earth's age to be under a hundred thousand years, extrapolating from the cooling of heated iron balls. At the time, there was good corroboration for Thompson's calculations. The qualitative statements of those like Lyell and 
Darwin were the only argument against such a young Earth, and Darwin's use of the denudation of the Weald as evidence for an ancient Earth was later expunged from On the Origin of Species. Darwin and Lyell were being highly theoretical in their argument for an ancient Earth during a time when objective observations took precedence over theory. An ancient Earth is only obvious, again, in hindsight.

Bjornerud (p. 67) relates the story of Fred Vine and Drummond Matthews concerning their benchmark paper often cited as the beginning of the plate tectonics revolution. She states that they

proposed seafloor spreading on the basis of a perceptive geometric argument rather than first-hand geologic observation (the ridges would not be directly seen or sampled for another decade). Vine and Matthews had access not only to Tharp's maps but also to data from the US in the Royal Navy's magnetic signatures of rocks at the bottom of the ocean.

In fact, it was Harry Hess in 1960 who proposed the mechanism, which was later coined "seafloor spreading" by Robert Dietz. What the Vine and Matthews paper did was to connect seafloor spreading with the magnetic stripes on the seafloor and the calibrated geomagnetic reversal time scale, showing that they were all coherent. Their work brought together the knowledge from groups working independently of each other; where none had been actually working on the question of continental drift-what would soon become known as the new global tectonics.

In addition to these historical inaccuracies, I noted a couple of science content errors I think worthy of correcting: they are common misconceptions and, as a teacher, I believe it is important not to propagate them. Bjornerud states that "carbon-14 is produced when a nitrogen-14 $\left({ }^{14} \mathrm{~N}\right)$ atom high in the atmosphere is struck by cosmic ray with energy enough to knock a proton out of the nitrogen nucleus" (p. 50). However, if a proton is knocked out of the nucleus of the nitrogen atom, then that leaves only 13 nuclear particles, making the product carbon-13. What actually is thought to happen is that cosmic rays collide with particles in the air, creating energized neutrons. When an energized neutron collides with a nitrogen atom, a proton does leave, but the neutron stays, keeping the atomic weight at 14 .

Another common misconception that occurs in numerous texts is this idea: "The symmetrical pattern of magnetic stripes suggested that successive generations of ocean crust had formed at the ridge, cool enough for their iron bearing minerals to align with the ambient magnetic field" (p.68). In this case, basalts, normally molten above $1000^{\circ} \mathrm{C}$, will in fact be solid before cooling to the Curie temperature (about $570^{\circ} \mathrm{C}$ ), the temperature at which the iron bearing minerals will assume the ambient magnetic field. No alignment of mineral grains to the magnetic field happens because the rock is already solid at the Curie temperature. Mineral alignment can happen in sedimentary rocks to an extent, where grains can align if they have the time while settling out in a column of water - but it will not happen in cooling magma.

Finally, with a description of isostasy, the buoyant force of the mantle holding up the lithosphere, Bjornerud (p. 83) writes that weathering and erosion dominate topographic change after a mountain range becomes stable:

This causes the displaced mantle to flow back into place and the mountains to rise in elevation, like a ship emptied of cargo (such isostatic rebound also occurs in areas previously covered by thick sheets of glacial ice). In this way, erosion paradoxically helps raise mountains. 
This statement is a bit misleading because the mountains, if only subject to erosion, will be lowering (due to erosion) and rising (due to isostasy) at the same time, but not to the same extent. Like an iceberg, one tenth is above water and the other nine tenths are below. If I cut that iceberg down immediately to sea level, it would rise back up, but not to the original height. Ten percent of what is left of the iceberg will be above the water, which is a smaller amount than the original above-water height. So, what is happening with isostasy is that deep rocks are being raised to the surface to face these processes of weathering and erosion, but the mountains are not getting any taller, as implied by Bjornerud's analogy to the boat, as the boat does indeed float higher. Instead, they just are not showing the rate of decreasing elevation as the rate of erosion would imply.

\section{To Sum}

As I stated at the outset, reviewing this book has been a great opportunity to reflect on my own geologic knowledge and teaching experience. I really wanted to like the book. I really wanted to be able to derive a better and more useful way of thinking about time, which I could then demonstrate to my students for their own intellectual growth. I found the book to be a quick and easy read and believe that novices to geology would not find it difficult to understand most of the content. Bjornerud did a terrific job with personal anecdotes (perhaps the best part, in my mind) that were both timely and illustrative of her points, and she used metaphors well. What really caught my attention was how Bjornerud emphasized systems thinking. This is certainly a way to think about geoscience and seemed to dominate over timefulness as a major theme of the work. She definitely dropped some true pearls of wisdom throughout the text.

Unfortunately, I feel that the overall tone of the book, a tone steeped in scientism, creates outcomes that are counterproductive to the purpose of the book. First, this implies that science is the only way to understand the universe; if you are not a believer in all of science, then Bjornerud especially does not have much time or patience for you. This is potentially quite alienating to those who could really benefit from reading the more positive messages of the book. It creates a tone of cynicism that, frankly, could turn-off many would-be readers. A more positive message would attract more readers. For instance, she berates those who, in good faith, try to teach the scale of geologic time by expressing it on a $24-\mathrm{h}$ clock, calling them "wrongheaded, and even irresponsible" (p. 16). She espouses that this "suggests a degree of insignificance and disempowerment...[and] is psychologically alienating" (p.16). However, she could instead offer ways to make this analogy seem more affirmative and affirming. As a teacher, if someone told me what I was doing (with my best intentions in mind) was wrongheaded and irresponsible - but added nothing constructive to make a positive change-I would stop listening. Here, that translates to not bothering to finish the book.

The second consequence of Bjornerud's underlying scientism is how it prevents clear expressions of the way geological thinking indeed happens. Looking at past understandings of geology from the point of view of what we know today provides readers with no understanding of how these early geologists went about addressing the problems they had; how today's geologists attempt to address today's problems. By claiming phenomena (especially unobservable phenomena, like mantle convection) to be the cause of topographical features (like mid-oceanic ridges), she leaves out that these unobservable phenomena are only 
constructs inferred from and designed to explain the signs that we observe, the topographic features. To be fair, this is not solely an issue with Bjornerud's writing on geology. It matches the standard portrayal in just about any textbook that I've read. However, if thinking like a geologist is important for saving the world, as Bjornerud's title claims and I also believe, then we should model that thinking as much as possible. We should highlight more of the processes geologists undertake as they solve the world's problems: interpretation, systems thinking, abductive reasoning, and yes, timefulness.

\section{Compliance with Ethical Standards}

Conflict of Interest The author declares no conflict of interest.

Open Access This article is licensed under a Creative Commons Attribution 4.0 International License, which permits use, sharing, adaptation, distribution and reproduction in any medium or format, as long as you give appropriate credit to the original author(s) and the source, provide a link to the Creative Commons licence, and indicate if changes were made. The images or other third party material in this article are included in the article's Creative Commons licence, unless indicated otherwise in a credit line to the material. If material is not included in the article's Creative Commons licence and your intended use is not permitted by statutory regulation or exceeds the permitted use, you will need to obtain permission directly from the copyright holder. To view a copy of this licence, visit http://creativecommons.org/licenses/by/4.0/.

Publisher's Note Springer Nature remains neutral with regard to jurisdictional claims in published maps and institutional affiliations. 